(c) American Dairy Science Association, 2005.

\title{
Proteases Involved in Mammary Tissue Damage During Endotoxin-Induced Mastitis in Dairy Cows*
}

\author{
J. Mehrzad, ${ }^{1,2}$ C. Desrosiers, ${ }^{1}$ K. Lauzon, ${ }^{2}$ G. Robitaille, ${ }^{3}$ X. Zhao, ${ }^{2}$ and P. Lacasse ${ }^{1}$ \\ ${ }^{1}$ Dairy and Swine Research and Development Centre, Agriculture and Agri-Food Canada, \\ Lennoxville, QC, Canada, J1M 1 Z3 \\ ${ }^{2}$ Department of Animal Science, McGill University, 21111 Lakeshore Road, \\ Ste. Anne de Bellevue, QC, Canada, H9X 3V9 \\ ${ }^{3}$ Food Research and Development Centre, Agriculture and Agri-Food Canada, \\ St-Hyacinthe, QC, Canada
}

\begin{abstract}
During and after diapedesis, milk polymorphonuclear neutrophils (PMN) release many proteases that have the potential of degrading extracellular matrix proteins and milk proteins. However, the kinetics of milk proteolysis during inflammation and the underlying mechanisms are poorly defined. The enzymes involved in bovine mammary tissue destruction were investigated in this study using an endotoxin-induced mastitis model. Using zymography techniques, the proteolytic activity of milk and mammary tissue during mastitis was examined. Mastitic milk produced 6 caseolysis bands, 4 of which differed from the ones produced by plasmin. Peak proteolytic activity, bovine serum albumin contents, and mammary tissue damage occurred between 6 and $12 \mathrm{~h}$ postchallenge. Mastitic milk proteases hydrolyzed casein, gelatin, collagen, hemoglobin, mammary gland membrane proteins, and lactoferrin. These results confirm that mastitic milk proteases have a broad spectrum of activity. The hydrolytic activity of mastitic milk was partially inhibited by aprotinin, EDTA, 1,10-phenanthroline, leupeptin, and pefabloc. When cocultured with normal mammary tissue, mastitic milk, but not normal milk, caused mammary tissue degradation. In situ zymography of mammary gland showed increased proteolytic activity in mastitic tissue compared with normal tissue. The similarity of zymograms of mastitic milk, blood PMN, milk somatic cells, and PMN strongly suggests that proteases in mastitic milk mainly originate from milk PMN. These results suggest that proteases released by PMN are actively involved in udder tissue damage during mastitis.
\end{abstract}

(Key words: endotoxin mastitis, mammary gland, matrix metalloproteinase, protease)

Received March 29, 2004.

Accepted October 4, 2004.

Corresponding author: Pierre Lacasse; e-mail: lacassep@agr.gc.ca.

*Dairy and Swine Research and Development Centre contribution no. 836 .
Abbreviation key: MMP = matrix metalloproteinase, OD = optical density, $\mathbf{P C H}=$ postchallenge hour, $\mathbf{P M N}=$ polymorphonuclear neutrophils, $\mathbf{R O S}=$ reactive oxygen species, $\mathbf{S C}=$ somatic cells.

\section{INTRODUCTION}

Because they are involved in degradation of matrix proteins and milk proteins during mastitis, proteases have recently become of interest in relation to physiological and pathological events of mastitis (Long et al., 2001; Raulo, et al., 2002). Transmigrated polymorphonuclear neutrophils (PMN) release reactive oxygen species (ROS) and many proteolytic enzymes before and during inflammation (Mehrzad et al., 2001; Burvenich et al., 2003). The proteases and ROS of PMN are interrelated (Reeves et al., 2002), and tissue PMN, particularly from inflamed tissue, are almost resistant to cytokinemediated activation/inhibition (Hotta et al., 2001). It is generally accepted that proteases enhance the bactericidal capacity of PMN (Reeves et al., 2002), accelerating resolution of infection. In lesions associated with acute inflammation, bacterial endotoxin damages tissue mainly by attracting PMN that, in turn, release damaging substances (Birkedal-Hansen, 1993). The pathogenesis of the mammary tissue damage is multifactorial. One interesting example is the involvement of extracellular ROS (Mehrzad et al., 2001; Mehrzad, 2002) and proROS cytokines (Shuster et al., 1997) of PMN in mammary tissue damage during mastitis. Production of ROS and proROS cytokines in milk is extremely high throughout d 1 of endotoxin mastitis (Hagiwara et al., 2001; Mehrzad et al., 2001), potentially boosting mammary tissue damage. Proteases may be another factor contributing to this damage (Burvenich et al., 2003).

Normal milk contains many endogenous proteolytic enzymes (Fox, 1992). An active serine protease, plasmin (E.C. 3.4.21.7), hydrolyzes casein and tissue proteins. The activity of plasmin is controlled by a cascade of events linked largely to plasminogen, plasminogen activators ( $u$ - and t-types), and plasminogen activator in- 
hibitors (Grufferty and Fox, 1988). The plasmin system has been widely investigated in normal (Heegaard et al., 1994) and mastitic milk (Kaartinen et al., 1988; Zachos et al., 1992). Compared with normal milk, mastitic milk has higher levels of several enzymes, especially proteases (Heegaard et al., 1994; Long et al., 2001; Raulo et al., 2002) that could potentially damage mammary tissue. The mechanisms responsible for mammary epithelium and tissue damage during mastitis are not well known. Only a few studies have been performed on the nonplasmin enzymes associated with milk somatic cells (Verdi and Barbano, 1991; Long et al., 2001; Raulo et al., 2002). During mastitis, high proteolytic activity (Raulo et al., 2002) leads to a protease-antiprotease imbalance and tissue damage (Nickerson and Heald, 1981), requiring the application of antiproteases to maintain homeostasis within the inflamed udder. Several synthetic antiproteolytic substances are available (Burns et al., 1990), and clinical applications have been developed to control inflammatory diseases in human and animals, e.g., gingivitis (Birkedal-Hansen, 1993) nephritis (Özer et al., 2001), and ulcerative keratitis (Ollivier et al., 2003). Consequently, there may be opportunities for pharmacological intervention to block the proteolytic cascade within the inflamed gland during mastitis. In this study, our objective was to better characterize proteolytic activity in the mammary gland during mastitis and its effect on integrity of mammary tissue.

\section{MATERIALS AND METHODS}

\section{Animals and Experimental Procedures}

All animals were treated according to the guidelines of the Canadian Council on Animal Care and experimental protocols were approved by the Dairy and Swine R\&D Center Animal Care Committee. Nine healthy high-yielding dairy cows in midlactation were used. Mastitis was induced in 8 cows as follows: immediately after the morning milking, left hindquarter was infused with $10 \mathrm{~mL}$ of saline containing $15 \mu \mathrm{g}$ of Escherichia coli purified LPS (Sigma Chemical Co., St. Louis, MO). Right hindquarter received $10 \mathrm{~mL}$ of sterile saline (control quarter). Milk samples were taken at postchallenge hour (PCH) -1, 3, 6, 9, 12, 24, 36, 48, 60, and 72. The milk samples were defatted by centrifugation $(400 \times g$, $10 \mathrm{~min}, 4^{\circ} \mathrm{C}$ ). After carefully removing cream, samples were kept at $-20^{\circ} \mathrm{C}$ for subsequent analysis. The same experimental design was used for another cow except that a dose of $100 \mu \mathrm{g}$ of LPS was used to elicit a maximum inflammatory response. At PCH 9, this cow was euthanized by electrocution and the mammary gland was carefully dissected. Tissue samples $\left(\sim 3 \mathrm{~cm}^{3} ; \mathrm{n}=6\right)$ were taken from control and inflamed quarters, and immediately placed in $40 \%$ buffered formaldehyde for histopathological examination or embedded in O.C.T. (Tissue Tek O.C.T. Compound, Sakura Finetek, CA) and frozen in liquid nitrogen without fixation. Blocks of the $1-\mathrm{cm}^{3}$ embedded tissue samples were stored at $-80^{\circ} \mathrm{C}$ until sectioning. The tissues were sliced with a cryomicrotome (IEC model Minotome Microtom Cryostat, Needham Heights, MA). Briefly, the sections (8$\mu \mathrm{m}$ thick) were cut on a motor-driven cryostat fitted with a reaction microtome at a cabinet temperature of $-25^{\circ} \mathrm{C}$. The sections were kept at $-80^{\circ} \mathrm{C}$ until use.

\section{Blood, Milk Cells, and Lactoserum}

Before LPS challenge, blood samples were taken from cows and small aliquots of blood and serum were immediately frozen and kept at $-20^{\circ} \mathrm{C}$. Polymorphonuclear neutrophils were isolated using hypotonic lysis. Briefly, $15 \mathrm{~mL}$ of heparinized blood was diluted with $15 \mathrm{~mL}$ of PBS (0.01 $M$ sodium phosphate, $\mathrm{pH} 7.2$, containing 0.15 $M \mathrm{NaCl}$ ), gently poured and layered into Falcon tubes containing $20 \mathrm{~mL}$ of Ficoll-Plaque Plus (Pharmacia, Montreal, QC), and centrifuged $\left(500 \times g, 40 \mathrm{~min}, 4^{\circ} \mathrm{C}\right)$; the plasma and Ficoll were gently discarded. About 10 $\mathrm{mL}$ of the blood packed cell was lysed by adding $15 \mathrm{~mL}$ of Tris-buffered $0.15 \mathrm{M}$ ammonium chloride and gently mixed for 5 min using a magnetic stirrer; $15 \mathrm{~mL}$ of PBS was added to the suspension and centrifuged $(300 \times g$, $10 \mathrm{~min}, 4^{\circ} \mathrm{C}$ ). For the second lysis procedure, the pellet was resuspended in $10 \mathrm{~mL}$ of PBS and lysis was conducted as described above. The remaining cell pellet was washed $\left(300 \times g, 5 \mathrm{~min}, 4^{\circ} \mathrm{C}\right)$ twice with $\mathrm{PBS}$ and the final cell pellet was resuspended in 1 to $2 \mathrm{~mL}$ of PBS for further analyses. Milk cells were harvested according to a previously described method (Mehrzad et al., 2001). Briefly, $50 \mathrm{~mL}$ of milk was diluted in 50 $\mathrm{mL}$ of PBS and centrifuged $\left(900 \times g, 15 \mathrm{~min}, 4^{\circ} \mathrm{C}\right)$. The pellets were suspended and twice washed $(300 \times g, 5$ min, $4^{\circ} \mathrm{C}$ ) in $10 \mathrm{~mL}$ of PBS. For blood and milk isolates, $50-\mu \mathrm{L}$ aliquots $\left(\sim 1 \times 10^{5}\right.$ cells $/ \mathrm{mL}$ of PBS, final concentration) were frozen and stored at $-20^{\circ} \mathrm{C}$ until further use. The lactoserum and casein fractions from normal and LPS-induced mastitic milk were separated by centrifugation $\left(107,000 \times g, 60 \mathrm{~min}, 4^{\circ} \mathrm{C}\right)$. The supernatants were divided into small aliquots and stored at $-20^{\circ} \mathrm{C}$ pending further analyses.

\section{Preparation of Mammary Gland Membrane Proteins and Collagen as Substrates}

Mammary gland membrane proteins were extracted from freeze-dried healthy mammary gland, which had been kept at $-80^{\circ} \mathrm{C}$. Briefly, $2.5 \mathrm{~g}$ of mammary gland tissue was homogenized in $0.25 M$ sucrose, $50 \mathrm{~m} M$ Tris 
$\mathrm{HCl}$ buffer ( $\mathrm{pH}$ 7.2), $1 \mathrm{~m} M \mathrm{MgCl}_{2}$, and $1 \mathrm{~m} M$ EDTA, containing $1 \mathrm{~m} M$ dithiothreitol, $1 \mathrm{~m} M$ phenylmethylsulfonyl fluoride, and $1 \mu M$ leupeptin. Homogenization was performed at $4^{\circ} \mathrm{C}$ with a Dounce-type glass-Teflon homogenizer for $8 \times 15 \mathrm{~s}$. The homogenate was then centrifuged $\left(1000 \times g, 10 \mathrm{~min}, 4^{\circ} \mathrm{C}\right)$, to remove nuclei and cell debris. To pellet membrane proteins, the supernatant was centrifuged $\left(105,000 \times g, 60 \mathrm{~min}, 4^{\circ} \mathrm{C}\right)$. The pellet, which contained only membrane proteins, was thoroughly washed in homogenization buffer without protease inhibitors, then stored at $-20^{\circ} \mathrm{C}$. Collagen was prepared from rat tail tendons according to Chandrakasan et al. (1976). After careful dissection, tendons were dried under UV light overnight then suspended in $1 \mathrm{~L}$ of $0.1 \%$ acetic acid solution and stirred for $3 \mathrm{~d}$ at $4^{\circ} \mathrm{C}$ until dissolved. The resulting viscous solution was aspirated through a $0.5-\mathrm{cm}$ diameter tube to disperse collagen and centrifuged $\left(10,000 \times g, 30 \mathrm{~min}, 4^{\circ} \mathrm{C}\right)$. Supernatant contained $5 \mathrm{mg} / \mathrm{mL}$ of collagen type I. Aliquots were stored at $-20^{\circ} \mathrm{C}$. Protein contents in each substrate were determined using commercial (Bio-Rad, Mississauga, ON, Canada) assay kits and the method of Lowry et al. (1951).

\section{Zymogram Technique for Proteolytic Assay}

Zymography was performed according to Raser et al. (1995) with some modifications. Briefly, the zymogram contained a $12 \%$ (wt/vol) acrylamide, $0.32 \%(\mathrm{wt} / \mathrm{vol}) \mathrm{bis}-$ acrylamide (N'N'-bis-methylene-acrylamide) gel in 375 $\mathrm{m} M$ Tris-HCl buffer ( $\mathrm{pH} 8.8$ ) to which $0.2 \%$ of each protein substrate, individually, was added; it was polymerized by adding $0.4 \%$ ( $\mathrm{vol} / \mathrm{vol}$ ) ammonium persulfate (10\% solution) and $0.05 \%(\mathrm{vol} / \mathrm{vol})$ TEMED (N,N,N',N'tetra-methylethylenediamide). A stacking gel, $4 \%$ acrylamide and $0.11 \%$ bis-acrylamide in $330 \mathrm{mM}$ Tris$\mathrm{HCl}$ buffer ( $\mathrm{pH} 6.8)$ with polymerizing agents $(0.4 \%$ ammonium persulfate $10 \%$ and TEMED $0.05 \%$ ), was poured over the zymogram gel. Following a prerun at $150 \mathrm{~V}$ for $15 \mathrm{~min}$ at $4^{\circ} \mathrm{C}$ to equilibrate the gel and remove noncopolymerized substrate from gel), nonreduced and nondenatured samples diluted in $150 \mathrm{mM}$ Tris- $\mathrm{HCl}(\mathrm{pH}$ 6.8), $20 \%$ glycerol, and $0.0004 \%$ (wt/vol) bromophenol blue were run at $150 \mathrm{~V}$ for $3 \mathrm{~h}$ at $4^{\circ} \mathrm{C}$. The running buffer was $25 \mathrm{~m} M$ Tris base, $192 \mathrm{~m} M$ glycine, $0.1 \%$ SDS, $\mathrm{pH}$ 8.3. Gels were removed from the casts and SDS was washed out by soaking in $2.5 \%$ Triton X-100 for $30 \mathrm{~min}$ at room temperature to renature the proteases. The gels were then washed (30 min at room temperature) in developing buffer containing $50 \mathrm{~m} M$ Tris $\mathrm{pH}$ 7.6, 0.2 $\mathrm{M} \mathrm{NaCl}, 5 \mathrm{mM} \mathrm{CaCl} 2$, and 0.02\% Brij 35 . Enzymatic activity was developed by overnight incubation of gels in the developing buffer at $37^{\circ} \mathrm{C}$. Finally, zymograms were stained in $0.1 \%$ Coomassie blue R-250 in $40 \%$ methanol and $10 \%$ acetic acid for $30 \mathrm{~min}$ and destained, several times, with $40 \%$ methanol and $10 \%$ acetic acid until clear proteolysis bands appeared on a dark-blue background. The zymograms were scanned with an Imaging Densitometer, model GS-670 (BioRad) and analyzed using molecular analyst software (Bio-Rad). Using the zymogram technique, the kinetics of protease activity in milk during LPS mastitis was evaluated on gelatin and casein. Molecular weights were calculated during the zymographic analysis using standards ranging from 18.4 to $216 \mathrm{kDa}$ (Kaleidoscope Prestained Standards, Bio-Rad).

Total proteolytic activity was calculated after videodensitometry analysis of the negative images of the casein and gelatin zymograms. The intensity of each lysis band was quantified and total proteolytic activity was obtained by adding up the optical densities measured in each lane. The results were arbitrarily expressed as optical density (OD).

\section{Determination of Plasmin and BSA in Milk}

Plasmin activity was measured by a modified version of the colorimetric method described by Politis et al. (1993), using a microplate assay. After incubating 10 $\mu \mathrm{L}$ of milk and $190 \mu \mathrm{L}$ of $50 \mathrm{mM}$ Tris buffer ( $\mathrm{pH} 7.5)$ containing $110 \mathrm{~m} M \mathrm{NaCl}$ and $0.6 \mathrm{~m} M$ H-D-valyl-L-leucyl-L-lysine-p-nitroanilide dihydrochloride (V-7127, Sigma Chemical Co.) for $60 \mathrm{~min}$ at $37^{\circ} \mathrm{C}$, OD were read at $405 \mathrm{~nm}$ and plasmin activity was expressed in millimoles of substrate hydrolyzed per minute. A method to measure albumin in urine (Koupparis et al., 1985) was adapted to quantify BSA in milk. Briefly, $200 \mu \mathrm{L}$ of skim milk was added to $1 \mathrm{~mL}$ of water and $1 \mathrm{~mL}$ of bromocresol green working solution [one volume of 1.2 $\mathrm{m} M$ bromocresol green in $5 \mathrm{~m} M \mathrm{NaOH}$ with 3 volumes of $0.2 \mathrm{M}$ succinic acid, $\mathrm{pH} 4.0$, and $0.8 \%$ (vol/vol) Brij $35]$. Tubes were centrifuged $\left(2500 \times g, 10 \mathrm{~min}, 4^{\circ} \mathrm{C}\right)$ to pellet casein. To calculate BSA concentrations in the samples, the supernatants' OD were read at $640 \mathrm{~nm}$ and compared with standard curve values (0 to $60 \mathrm{mg}$ of $\mathrm{BSA} / \mathrm{mL}$ of reconstituted commercial powdered milk).

\section{Somatic Cell Count}

Individual quarter milk samples $(50 \mathrm{~mL})$ were collected for SCC determination throughout LPS mastitis by Program d'Analyze des Troupeaux Laitiers du Québec (PATLQ; Ste-Anne-de-Bellevue, QC).

\section{Proteolytic Activity in Blood and Milk Components}

Defatted mastitic milk, mastitic and normal lactoserum or casein, mastitic and normal milk cells, 
whole blood and nonactivated blood PMN were run simultaneously on gelatin and casein zymograms. Samples were diluted to give a final protein concentration of $1 \mu \mathrm{g} / \mu \mathrm{L}$, and $10 \mu \mathrm{g}$ of protein was loaded per lane. To compare milk cell proteolytic profiles with different proteases, mastitic milk lactoserum and commercial proteases associated with inflammation were run simultaneously in zymograms. Five micrograms of plasmin, $7.9 \mu \mathrm{g}$ of cathepsin D (EC 3.4.23.5), $1 \mu \mathrm{g}$ of elastase (EC 3.4.21.37), $3 \mu \mathrm{g}$ of stromelysin-1 (MMP-3, EC 3.4.24.17), and $1 \mu \mathrm{g}$ of collagenase III (Sigma Chemical Co.) were run together and compared with $3 \mu \mathrm{L}$ of mastitic lactoserum on a gelatin zymogram. The selected amounts of commercial proteases and mastitic lactoserum were in accordance with our preliminary experiments, and were appropriate to observe clear lysis bands with of similar intensities on zymograms.

\section{Substrate Specificity for Proteases Characterization}

In substrate specificity analyses, several proteins were used as substrates to be copolymerized with precast polyacrylamide gels. Mastitic and nonmastitic lactoserums were loaded on these zymogram gels and their proteolytic activities on the various protease substrates were compared. Collagen type I and mammary gland membrane proteins were prepared in our laboratory as described above. Gelatin, casein, hemoglobin, and lactoferrin were from Sigma and Calbiochem-Novabiochem International (Interscience, Markham, ON, Canada). Zymography was performed as described above.

\section{Effect of Protease Inhibitors}

Various protease inhibitors were purchased from Boehringer-Mannheim (Laval, QC). The stock solutions of aprotinin, EDTA, leupeptin, and pefabloc were dissolved in $\mathrm{H}_{2} \mathrm{O}$ and the stock solution of 1,10-phenanthroline was dissolved in methanol. The protease inhibitor assay was done on isolated lanes of a normal zymogram containing mastitic milk during the developing step of the zymography. To do this, aprotinin $(0.3 \mu M$, final concentration), 1,10-phenanthroline $(0.1 \mathrm{mM}$, final concentration), EDTA (5 $\mathrm{m} M$, final concentration), leupeptin ( $1 \mu M$, final concentration), and pefabloc (0.4 $\mathrm{m} M$, final concentration) were separately added in the developing buffer, and the gels were soaked and incubated overnight at $37^{\circ} \mathrm{C}$. The gels were then stained with Coomassie blue, and proteolytic inhibition was followed according to the number and intensity of lysis bands on the gels.

\section{Effects of Mastitic Milk on Mammary Tissue}

Tissues from the control quarter of the euthanized cow were selected and the normal status of the tissue was confirmed using standard histology techniques (stained with Hematoxylin-Eosin) and microscopic observations. The absence of leukocyte infiltration, especially PMN, in the ductular and alveolar parts of the quarters was a strong indicator of normal mammary tissue. Cryosections were incubated for $24 \mathrm{~h}$ at $37^{\circ} \mathrm{C}$ with normal or mastitic lactoserum. After incubation, the tissues were stained with Fast Green and Sirius Red in saturated picric acid as described by Lopez-De Leon and Rojkind (1985). The samples were examined microscopically and pictures were taken at 100 to $400 \times$ magnification with a camera (Rico Co., Tokyo, Japan) coupled to the microscope.

\section{Proteolytic Activity of Mastitic Tissue}

To assess net proteolytic activity of inflamed udder, in situ zymography was developed as previously described (Galis et al., 1995). Briefly, thin sections (8- $\mu \mathrm{m}$ thick) of normal and inflamed mammary tissues (at PCH 9) were layered on a gel containing substrate and gelatin, or on a gelatin-coated x-ray film (Kodak, Scientific Imaging Film X-OMAT AR). The tissue slices were incubated overnight at $37^{\circ} \mathrm{C}$ in a humid chamber. After incubation, tissue slices were carefully removed. The acrylamide-gelatin gels were stained with Coomassie blue and x-ray films were exposed to light and developed. Results were photographed under microscope at $\times 100$ magnification with a camera (Rico Co.) coupled to the microscope.

\section{Statistical Analyses}

The Statistix program package (version 4.1, Analytical Software, Tallahassee, FL) was used for the statistical analyses. Because the values after LPS challenge were not normally distributed, a Kruskal-Wallis test was used to analyze the effects of LPS mastitis and to compare BSA, SCC, plasmin activity, and total proteolytic activity from just before mastitis induction (time 0 ) with the values at PCH $3,6,9,12,24,36,48,60$, and 72 using Bonferroni multiple comparisons at an adjusted significance level of 0.01 . The time of sampling was a fixed factor, cows were a randomized factor, and their interaction term was the error term.

\section{RESULTS}

\section{Clinical Signs}

Intramammary administration of LPS induced an increase of rectal temperature, heart rate, and respiration at around $\mathrm{PCH}$, as well as swelling and pain in the challenged quarters. Appearance of flecks and milk leakage in LPS-injected quarters was observed at PCH 


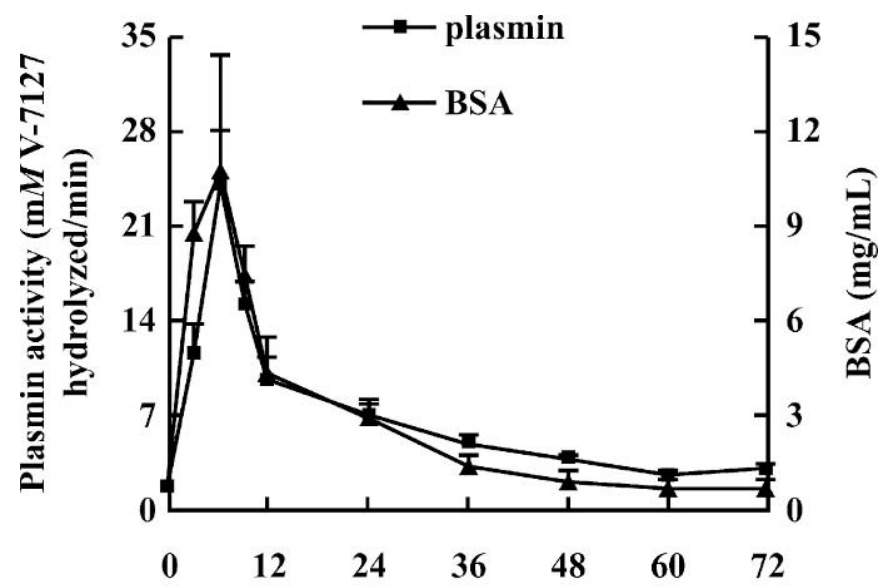

Hours relative to LPS infusion

Figure 1. Plasmin activity and BSA concentration in milk of cows during LPS-induced mastitis. Values are the mean \pm SEM of 8 cows. V-7127 $=0.6 \mathrm{~m} M$ H-D-valyl-L-leucyl-L-lysine-p-nitroanilide dihydrochloride.

3 to 6 (data not shown) for all cows. Decreased milk production was observed in inflamed and noninflamed quarters in $\mathrm{d} 1$ to 2 of inflammation, which was restored at PCH 72 (data not shown). Clinical signs of mastitis, except flakes in milk, disappeared around PCH 72.

\section{Concentrations of Plasmin and BSA in Milk}

Plasmin activity increased sharply from PCH 3 to 9 $(P<0.01)$, peaking at $25 \mathrm{~m} M$ of $0.6 \mathrm{~m} M \mathrm{H}$-D-valyl-Lleucyl-L-lysine-p-nitroanilide dihydrochloride (V-7127) hydrolyzed per min at PCH 6 (Figure 1). Like plasmin, BSA concentrations increased sharply $(P<0.01)$ in LPSinfused quarters at PCH 3 to 9 (Figure 1), peaking at $10 \mathrm{mg} / \mathrm{mL}$ at $\mathrm{PCH} 6$. The BSA concentration was undetectable before LPS challenge and no BSA appeared in control quarters during the challenge.

\section{Total Proteolytic Activity in Milk, and SCC}

Total proteolytic activity increased sharply $(P<0.01)$, reaching its maximum at $\mathrm{PCH} 9$ but its profile differed from that of plasmin: it remained high even at PCH $>12$ and decreased steadily afterwards (Figure 2).

Between PCH 6 and 12, a sharp increase of SCC was observed in LPS-injected quarters. The SCC in control quarters did not change significantly. Kinetics of milk proteolysis capacity on gelatin and casein zymograms showed that maximal milk proteolytic activity during endotoxin mastitis appeared at PCH 6 to 12 (Figure 3). From Figures 2 and 3 , it can be seen that with gelatin as a substrate, maximal proteolytic activity was reached at PCH 9, after which it decreased abruptly.

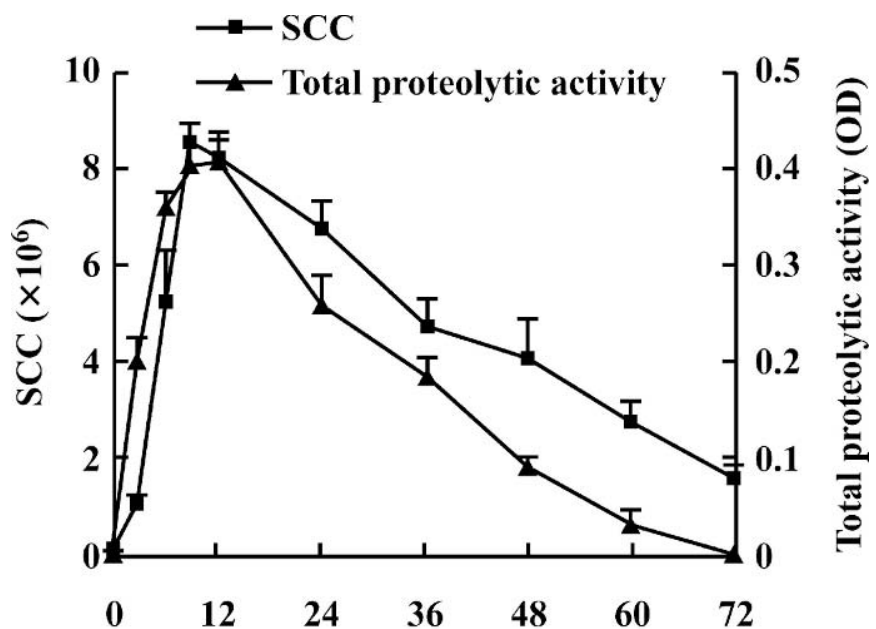

Hours relative to LPS infusion

Figure 2. Proteolytic activity (- $\boldsymbol{\Lambda}_{-}$) as measured by densitometric analysis of zymograms using casein and gelatin as substrates and SCC (- -) in milk of cows during LPS-induced mastitis. Values are the mean \pm SEM of 8 cows; OD = optical density.

On casein, however, the activity reached the normal pattern much more slowly, indicating that different proteases are implicated.

\section{Proteolytic Activity in Blood and Milk Components}

Comparison of proteolytic activity between mastitic milk at PCH 9 and plasmin in a casein zymogram revealed that the former produced at least 6 different caseolytic bands, whereas the latter produced only 3 bands. Only 2 of those bands, at around 48 and $91 \mathrm{kDa}$, could be matched (Figure 4). Other proteases present in mastitic milk seemed to be less charged or heavier proteins than plasmin because of their low migration speed. In addition, incubation with $500 \mathrm{~m} M \varepsilon$-aminocaproic acid, a plasmin inhibitor, reduced the intensity of the $91-\mathrm{kDa}$ band in mastitic milk slightly (data not shown), suggesting that this band is due to plasmin. The distribution and origin of mastitic proteases were investigated by comparing casein and gelatin zymogram profiles of milk, milk fractions, and blood. When gelatin was used as a substrate, proteolytic activity was observed in every sample tested except plasmin (Figure 5, upper panel). In the casein zymogram (Figure 5, lower panel), proteolytic activities appeared only with plasmin, mastitic milk, mastitic somatic cells (SC), and, to a lesser extent, mastitic lactoserum (Figure 5). A common protease, the lower band in the zymogram, was detected in milk, lactoserum, and casein fractions of normal and mastitic milk. Mastitic samples (milk, lactoserum, casein fraction, and SC) produced similar 

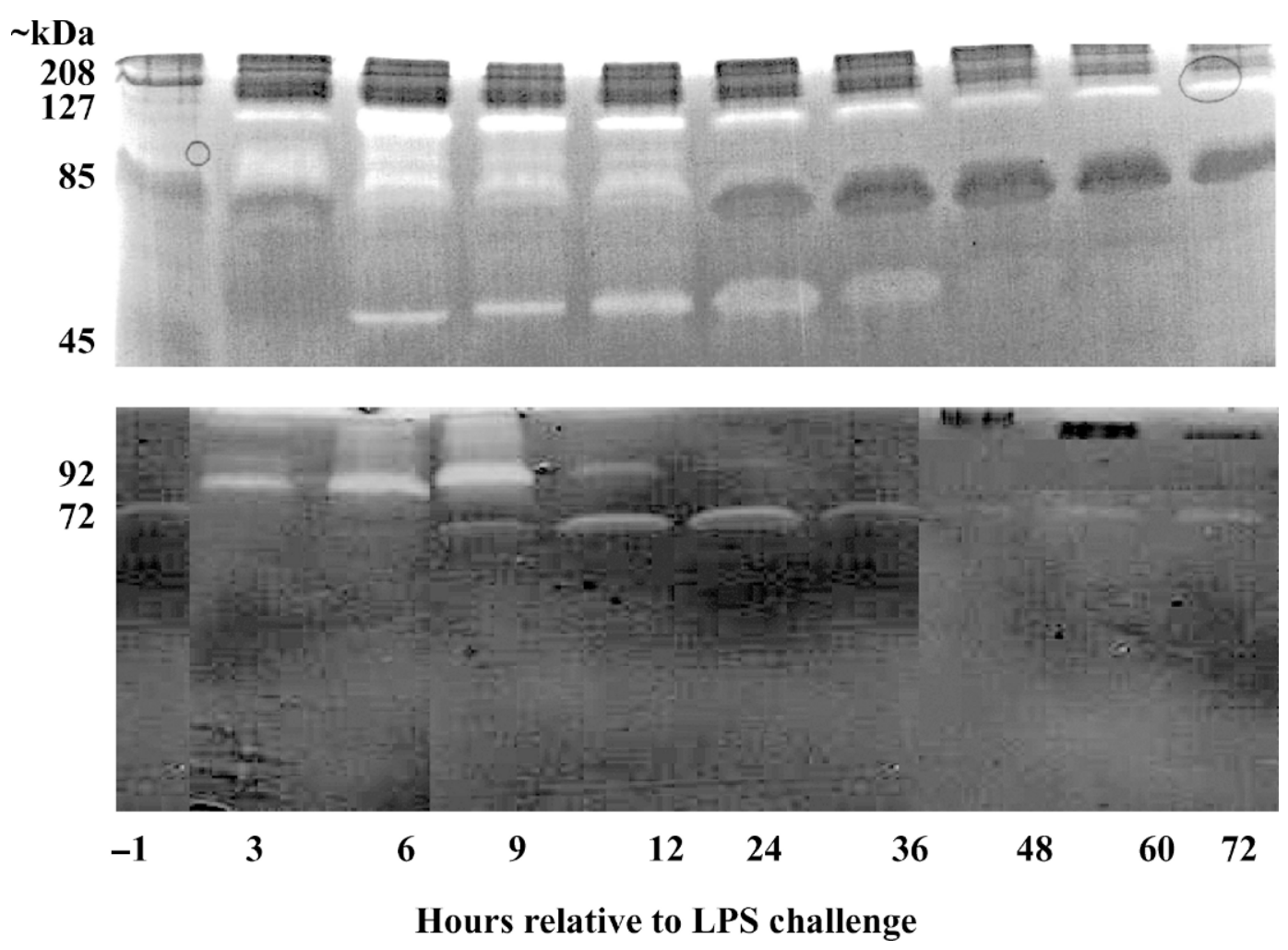

Figure 3. Kinetics of proteolytic activity of mastitic milk in casein (upper) and gelatin (lower) zymograms during LPS-induced mastitis.

proteolytic bands. Three common proteases were detected in blood and mastitic milk but their activities differed. Normal milk SC and nonactivated blood PMN had some bands in common with mastitic samples.

\section{Substrate Specificity}

Substrate specificity assays were performed to determine mastitic milk protease type(s) (Figure 6). Normal milk produced a single small lysis band of $\sim 80 \mathrm{kDa}$ in gelatin only. No lysis band was observed with other substrates. Conversely, mastitic milk hydrolyzed almost all substrates in decreasing order: gelatin, casein, collagen (type I), hemoglobin, mammary gland membrane protein, and lactoferrin. To compare milk cell proteolytic profiles with mastitis-related proteases, mastitic milk and commercial proteases associated with inflammation were run together and compared with mastitic lactoserum on a gelatin zymogram. This analysis indicates that mastitic milk proteolysis shares some functionality with collagenase, elastase, and stromelysin (Figure 6).

\section{Effect of Protease Inhibitors}

The relative efficiency of different protease inhibitors was evaluated in casein and gelatin zymograms (Figure
7). When casein was used as substrate, aprotinin, pefabloc, and EDTA inhibited completely the proteolytic activity of mastitic milk. In gelatin zymograms, a similar inhibition occurred in the presence of EDTA, 1,10phenanthroline, and aprotinin, and partial inhibition was observed with leupeptin.

\section{Histopathological Signs of Mastitis and Effects of Mastitic Milk on Mammary Tissue}

Examination of inflamed gland tissue revealed a large amount of exudates and PMN in the lumen and interstitial tissues, whereas these signs were not observed in noninflamed glands (Figure 8A, panels a and b). The ability of mastitic milk proteases to degrade normal mammary tissue was demonstrated after incubation of thin cryosections of normal mammary tissue with normal (Figures 8A, panels c and e) or mastitic lactoserum (Figures 8A, panels $\mathrm{d}$ and $\mathrm{f}$ ). The lighter staining seen in Figure 8A, panel d suggests massive degradation and removal of mammary connective tissues with mastitic lactoserum. Figure 8A, panel e shows that after $16 \mathrm{~h}$ incubation at $37^{\circ} \mathrm{C}$ with normal lactoserum, both the collagen network (stained with Sirius Red) and noncollagen proteins (stained with Fast Green) were apparent. When incubated with mastitic 


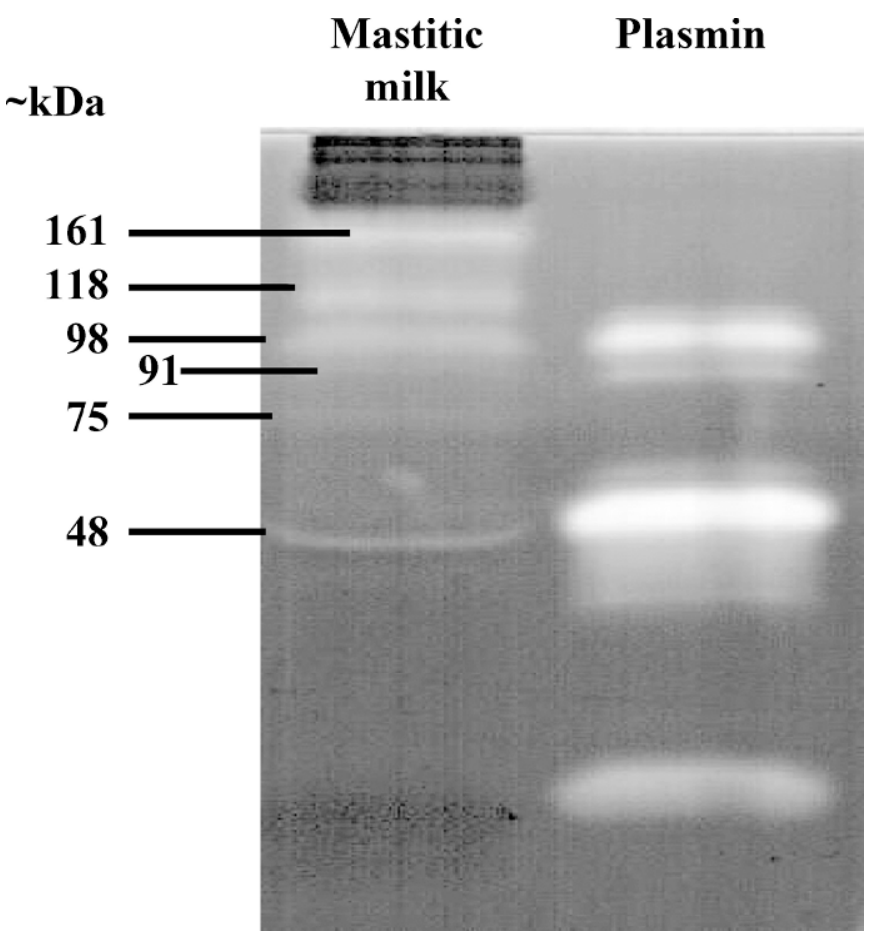

Figure 4. Comparison of mastitic milk (9 h after challenge) proteolytic activity with plasmin proteolytic activity in casein zymograms. Mastitic milk produced 6 caseolytic bands and plasmin 3 bands. Only 2 of these bands (at 48 and $91 \mathrm{kDa}$ ) are common to both.

lactoserum (Figure 8A, panel f), collagen network was still intact, but noncollagen proteins were not apparent. This suggests that cells had been removed.

\section{Proteolytic Activity of Mastitic Tissue}

In situ zymography of endogenous proteolytic activity in mastitic tissue revealed proteolytic activity in mammary tissue. Compared with normal mammary tissues, mastitic mammary tissues produced more gelatin lysis (Figure 8B) in both types of substrate support (gelatinacrylamide slab gel or x-ray film). Proteolysis was seen as clear zones on a blue or black background, mainly concentrated in alveoli structures and borders.

\section{DISCUSSION}

An endotoxin mastitis model was used to assess proteolytic activities in mastitic milk and mammary tissue during inflammation. The observed clinical signs of mastitis and BSA leakage in milk were similar to results described elsewhere (Bouchard et al., 1999; Mehrzad et al., 2001). The increases in BSA, plasmin, total proteolytic activity, and SCC point to the opening of mammary epithelial tight junctions and tissue damage. Because high SCC, predominantly PMN, can affect

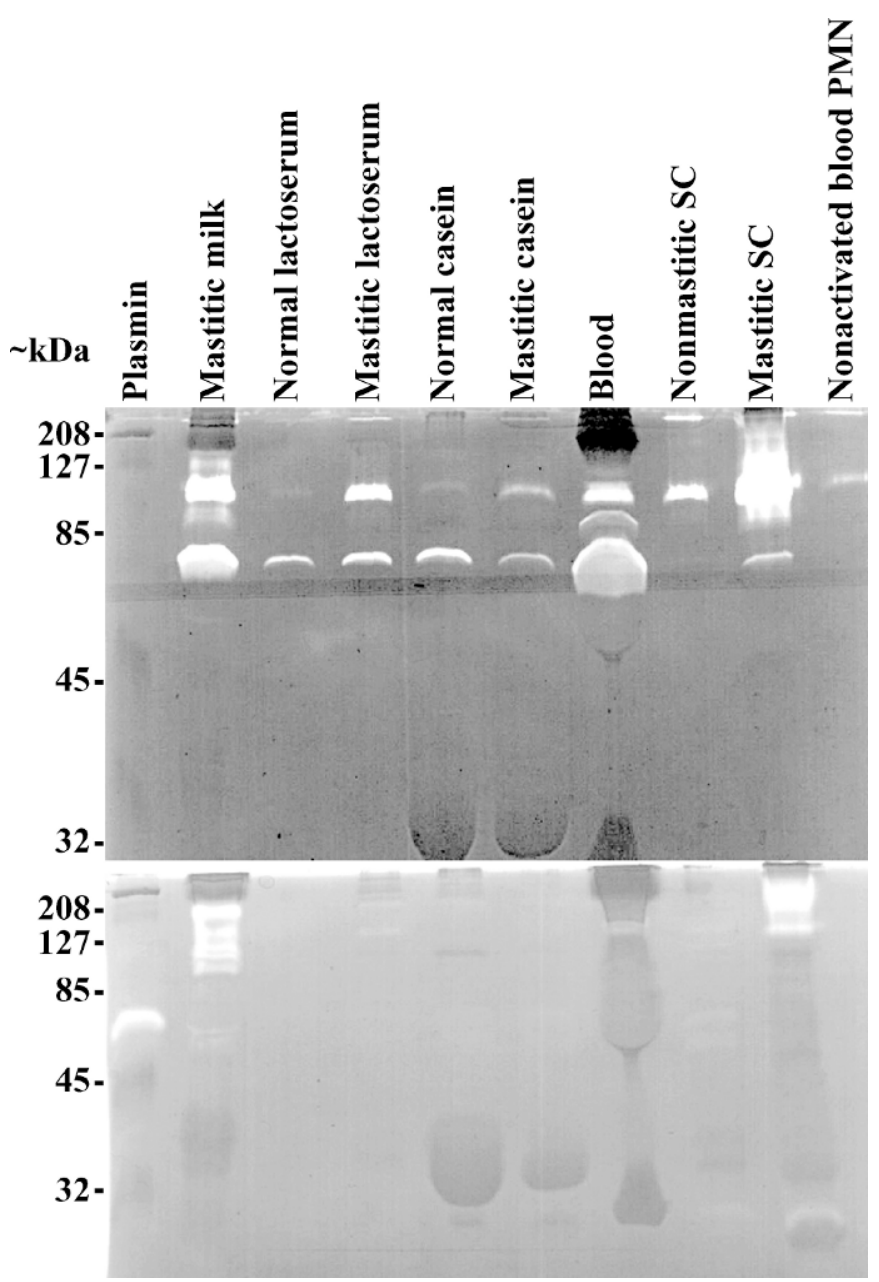

Figure 5. Comparison of zymogram profiles of milk, milk fractions, blood, and somatic cells (SC) from normal and LPS-induced mastitic quarters, and nonactivated blood polymorphonuclear neutrophils (PMN) on gelatin (upper panel) and casein (lower panel) substrates.

mammary tissue integrity, our study emphasizes that mastitic milk proteases are largely associated with milk PMN. A rapid increase of plasmin and total proteolytic activity in mastitic milk corresponded to the maximum number and intensity of lysis bands on both gelatin and casein zymograms at PCH 6 to 12 (see Figures 1, 2 , and 3 ). This confirmed peak destructive effects of proteases on blood-milk barrier.

The change in enzyme distribution and activity during inflammation was obvious. Maximum caseolysis corresponded to the maximum number of lysis bands on zymograms, but plasmin activity and total proteolytic activity did not follow exactly the same pattern. Mastitic milk contains many other active proteases in addition to plasmin (Zachos et al., 1992; Politis et al., 1993; Long et al., 2001). Comparison of mastitic milk enzymes with commercial plasmin revealed that they have 2 


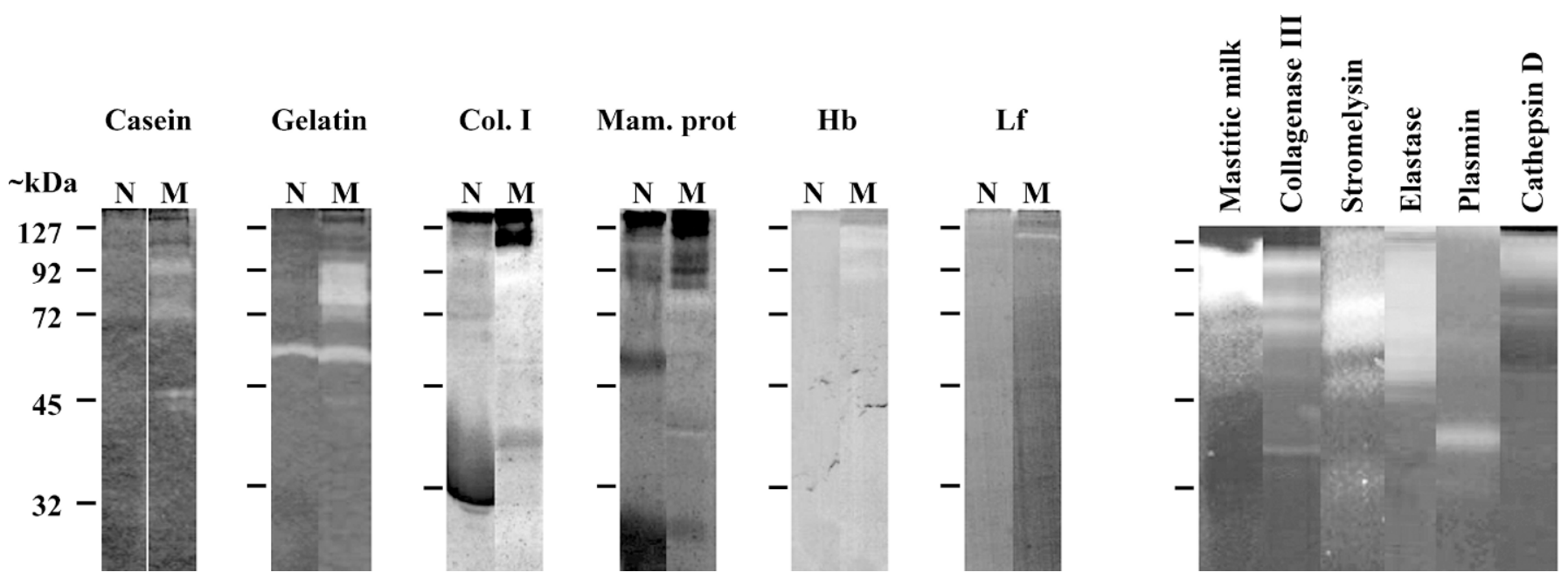

Figure 6. Substrate specificity assays to examine types of mastitic milk proteases. Normal milk produced lysis bands only with gelatin as a substrate. Mastitic milk produced lysis bands on gelatin, casein, collagen type I (Col. I), hemoglobin (Hb), mammary gland membrane protein (mam. prot), and lactoferrin (Lf; left panel). The right panel shows the mastitic milk proteases and commercial proteases on gelatin zymograms.

bands in common, 48 and $91 \mathrm{kDa}$. Because nonreducing conditions existed in zymography (Raser et al., 1995), the $91-\mathrm{kDa}$ band is close to the molecular weights of plasminogen $(90 \mathrm{kDa})$ and plasmin $(85 \mathrm{kDa})$. The differences in molecular size estimated in zymography can be explained by the less effective migration of protein in nondenaturing conditions. Additionally, copolymerized substrate in the gel could affect protease motility during electrophoresis. The lower band detected (48 $\mathrm{kDa}$ ) might be due to urokinase plasminogen activator. Indeed, the commercial plasmin was obtained by adding this serine protease to plasminogen. Urokinase plasminogen activator, which is present in bovine milk, is the predominant form of plasminogen activator associated with somatic cells (White et al., 1995). Furthermore, Staphylococcus aureus culture filtrate induces a 3 - to 10-fold increase in urokinase plasminogen activator activity in mammary cell-conditioned media and cellular lysates (Zavizion et al., 1997). Urokinase activity has been associated with $30-$ and $50-\mathrm{kDa}$ bands on SDS-PAGE under nonreducing conditions (White et al., 1995). However, urokinase has a narrow specificity and it is not known if it can hydrolyze casein. Given that casein micelle contains plasminogen (Heegaard et al., 1994), another possibility is that urokinase activates residual plasminogen associated with the zymogram substrate.

The protease activities of plasmin and mastitic milk were different. Normal milk produced a detectable proteolytic band only on gelatin, whereas mastitic milk produced many lysis bands on casein, gelatin, collagen type I, crude mammary gland membrane proteins frac- tion, hemoglobin, and lactoferrin, confirming the broadspectrum proteolytic activity of mastitic milk. In bovine, it has been suggested that plasmin is the main source of proteolytic activity in mastitic milk (Schaar and Funke, 1986; Verdi and Barbano, 1991; Fang and Sandholm, 1995). Because plasmin activity was undetectable on gelatin, and the proteolytic band at $\sim 100 \mathrm{kDa}$ is not indicative of plasmin activity, nonplasmin proteolytic activities must play a critical role in udder damage during mastitis.

During endotoxin mastitis, milk PMN represents more than $90 \%$ of the SC (Mehrzad et al., 2001). During PMN migration to the site of inflammation and PMN degranulation, many proteolytic enzymes are released, e.g., elastase, cathepsins (B, D, and G), and matrix metalloproteinases (MMP; Weiss, 1989), which are capable of destroying surrounding tissues. Elastase and cathepsin D have been found to exhibit proteolytic activity toward bovine casein (Considine et al., 2000). In a guinea pig model of acute lung injury induced by intratracheal instillation of $E$. coli LPS, massive recruitment of PMN occurred in conjunction with the presence of 68-, 72-, 92-, and $200-\mathrm{kDa}$ gelatinases in bronchoalveolar lavage samples assessed by zymography (D'Ortho et al., 1994; Larsen and Petersen, 1995). The 200- and 92-kDa gelatinases and elastase activities were also present in PMN-conditioned media of LPStreated animals (D'Ortho et al., 1994). Makowski and Ramsby (1996) reported that human blood contains 72-, 92-, 130-, and 225-kDa gelatinases, whereas plasma contains only the 72-kDa gelatinase, and PMN, the 92-, $130-$, and $225-\mathrm{kDa}$ gelatinases. These values are consis- 


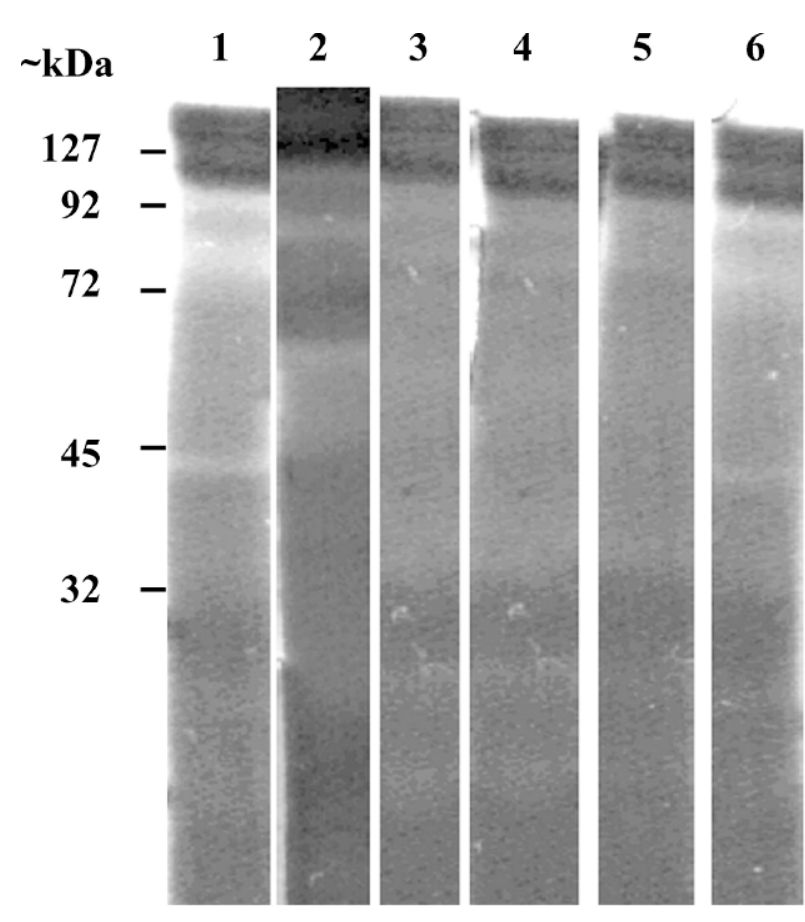

Gelatin

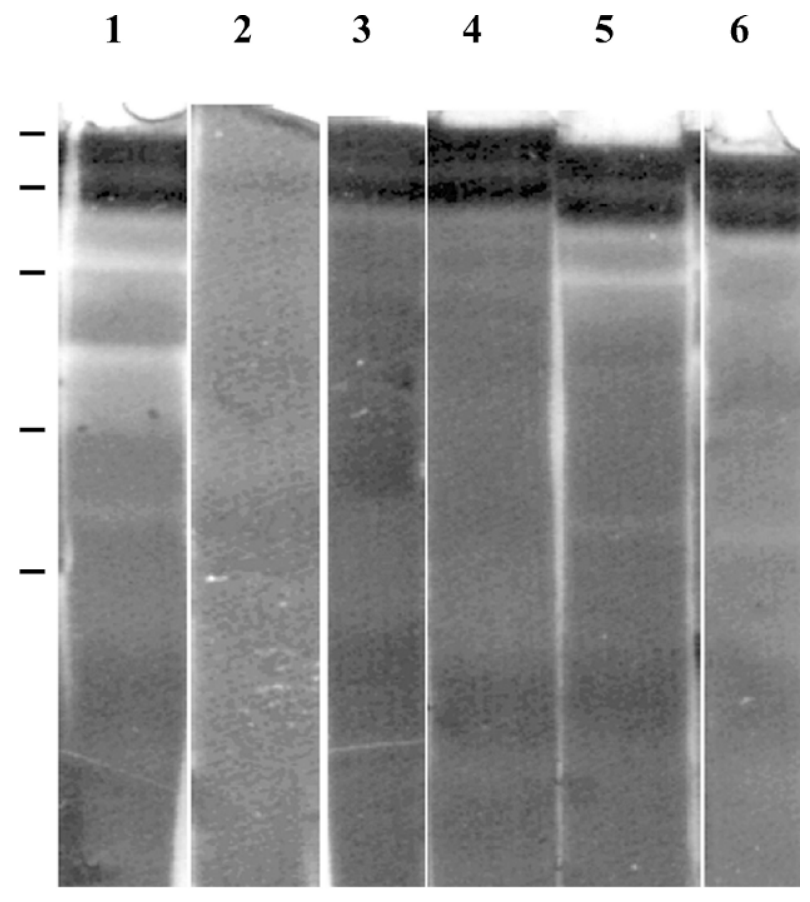

Casein

Figure 7. Efficiency of different protease inhibitors in gelatin (left panel) and casein (right panel) zymograms. Proteolytic activity of mastitic milk (lanes 1) was abolished by aprotinin (lanes 2), EDTA (lanes 3) 1,10-phenantroline (lanes 4), and partially by leupeptin (lanes 5 ), and pefabloc (lanes 6).

tent with bands seen with bovine blood, mastitic milk, mastitic lactoserum, and mastitic SC. When casein was used as a substrate, proteolytic activity was observed with plasmin, mastitic milk, mastitic somatic cells, and, to a lesser extent, mastitic lactoserum. When gelatin was used, plasmin produced no significant bands but all milk fractions tested produced proteolysis bands. Gelatinase activity was particularly high for mastitic SC. These results suggest that mastitic milk proteases are associated largely with milk PMN during udder inflammatory response. In apparent opposition with that, in situ zymography revealed that mastitic mammary tissue contains a higher proteolytic activity than normal tissue. However, this activity is probably linked to PMN migrating through the blood-milk barrier into the milk compartment.

Another approach used to assess the enzymatic characteristics of mastitic milk proteases related to tissue damage was the application of protease inhibitors. We showed that caseinolysis and gelatinolysis of mastitic milk were partially inhibited by adding EDTA, aprotinin, and 1,10-phenanthroline during the developing stage (stage of activation of proteolysis) of zymogram technique. Because aprotinin is a serine protease inhibitor (Verstraete, 1985) and 1,10-phenanthroline and
EDTA are MMP inhibitors, these findings strongly support the notion that endotoxin-induced mastitic milk contains substantial amounts of serine protease(s) and MMP(s). When a similar strategy was applied to normal human blood and PMN or LPS-treated guinea pig PMN and human trophoblasts, all gelatinase activities were inhibited by EDTA or 1,10-phenantroline (D'Ortho et al., 1994) and serine protease inhibitors (Nakatsuka et al., 2000). Moreover, leupeptin and pefabloc partially inhibited gelatin lysis. During past decades, efforts have been made to design protease inhibitors for humans and animal diseases. Some of the inhibitors studied appear to be promising for the treatment of bovine mastitis. Based on the findings of the present study and previous findings (Mehrzad, 2002), we suggest the application of antiproteolytic agents and antioxidants should be considered during mastitis therapy.

Mastitic milk proteolytic activities were tested directly in normal mammary tissue. Mastitic lactoserum produced higher proteolysis than normal lactoserum. Mastitic lactoserum exfoliated the cells and surrounding proteins, leaving a nude dense collagen network. These differences resulted from protease contents and activities, which were significantly higher in mastitic milk. Addition of 1,10-phenanthroline to mastitic 
A)
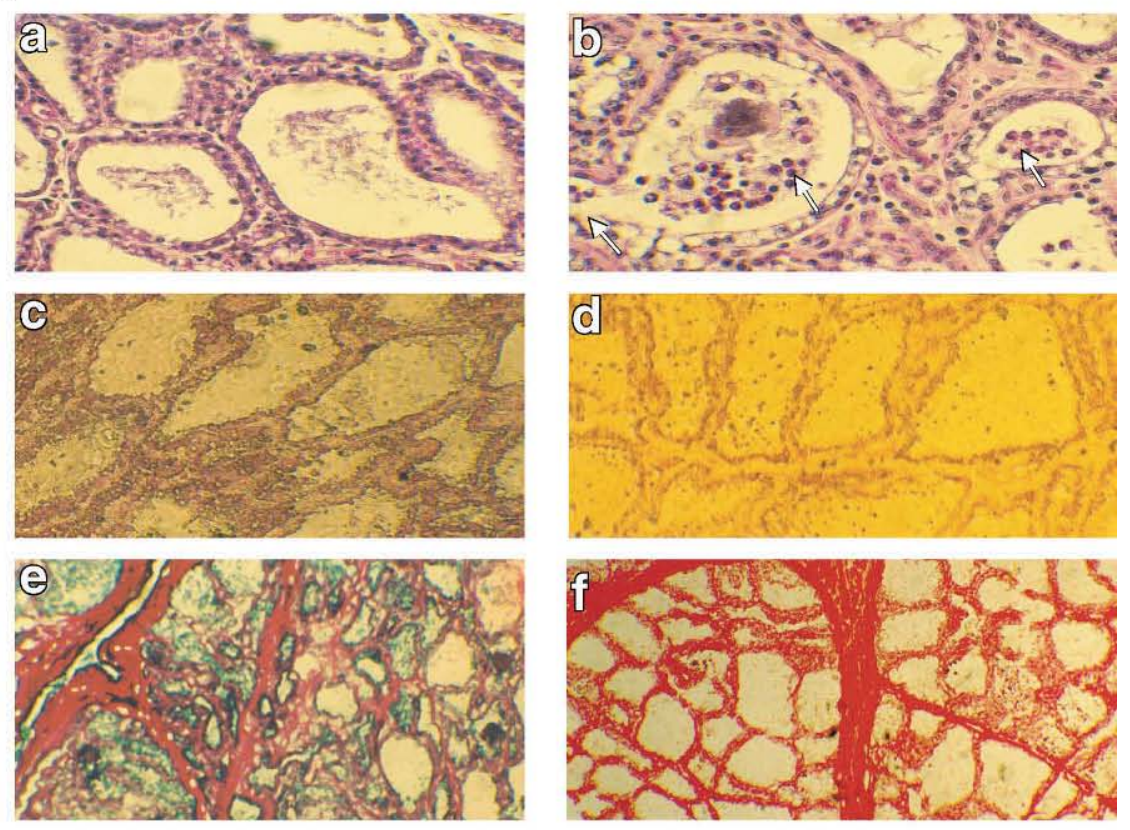

B)

X-ray film

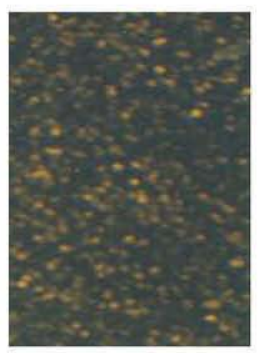

Normal

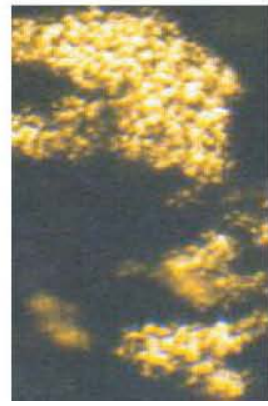

Gelatin polyacrylamide
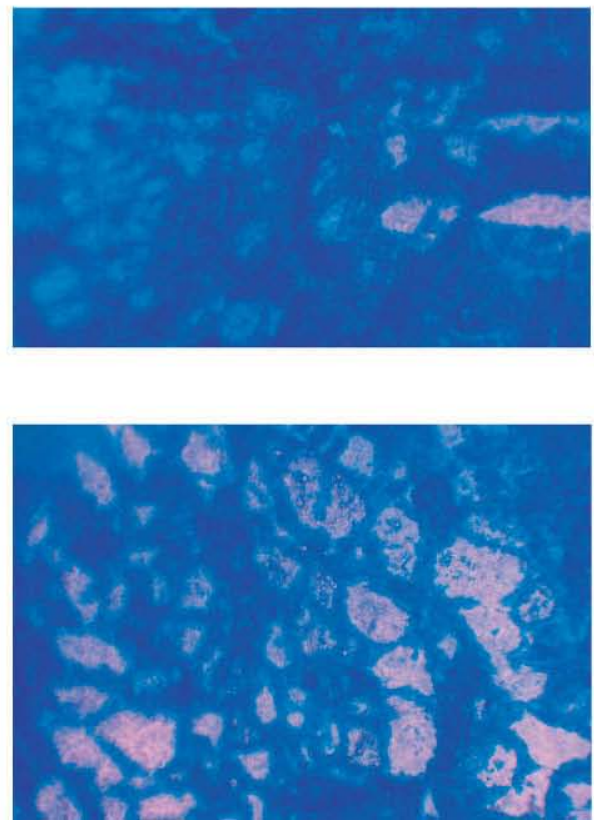

Figure 8. A. Histopathological examination of noninflamed mammary tissue (panel a; 400×) and LPS-induced mastitic tissue (panel b; 400x); the samples were taken $9 \mathrm{~h}$ after challenge. The influx of polymorphonuclear neutrophils in the ductular/alveolar part of the mastitic gland is visible (arrows); no such pattern is observed in noninjected quarters. Representative example of thin cryosection of normal mammary tissues incubated with normal (panel c; 100x) and mastitic (panel d; 100x) lactoserum. Degradation of normal mammary connective tissues with mastitic lactoserum is evidenced by less connective tissue and staining intensity in panel d. Histochemical examination of cryosections of normal mammary tissue incubated for $24 \mathrm{~h}$ at $37^{\circ} \mathrm{C}$ with lactoserum from control quarters (panel e; 100×) or from LPS-induced mastitic quarters (panel f; 100×). The tissues were stained with Fast Green and Sirius Red in saturated picric acid specific for proteins and collagen, respectively. After incubation with mastitic milk only the collagen structural network is visible. B. In situ zymogram of normal and inflamed mammary tissues (9 h after challenge) on x-ray film (left panels) or gelatin-polyacrylamide gel (right panels). Compared with normal mammary tissues, mastitic mammary tissues produced more gelatin lysis in gelatin-acrylamide slab gel and x-ray film. Proteolysis is seen as clear zones in a blue or black background and it is mainly concentrated in alveoli structures and borders (100×). 
lactoserum diminished exfoliation of cells from the tissue slices (data not shown), providing further evidence that the proteolysis and tissue damage observed in our study is largely due to MMP. To our knowledge, no study has been conducted on the proteolytic activities of MMP and their implication in bovine mastitis therapy. However, in other inflammatory diseases, e.g., respiratory disease (Koivunen et al., 1997), arthritis (van Meurs et al., 1999), renal lesions and nephritis (Zaoui et al., 2000), and postsurgery inflammation (Suzuki et al., 2000), PMN were found to be responsible for the release and activation of MMP and many other proteases. In these cases, application of antiproteolyic components proved promising.

In conclusion, mastitic tissue and milk exhibited pleiotropic effects on various proteins and contained highly active proteases. Plasmin is not the only protease involved in mammary tissue damage, and other very active proteases from PMN play a critical role in proteolysis and tissue damage. This finding may help to elucidate the pathophysiologic mechanisms and identify potential therapeutic targets for alleviation of mammary tissue damage during mastitis.

\section{ACKNOWLEDGMENTS}

This work was financed by a grant from the collaborative program of Novalait Inc. / Ministère de l'agriculture et des pêcheries du Québec / Fonds FQRNT and by Agriculture and Agri-Food Canada. Jalil Mehrzad was supported by a grant from Valorisation Recherche Québec and the Ministry of Science, Research and Technology of Iran. We thank Lisette St-James for her excellent technical assistance.

\section{REFERENCES}

Birkedal-Hansen, H. 1993. Role of cytokines and inflammatory mediators in tissue destruction. J. Periodont. Res. 28:500-510.

Bouchard, L., S. Blais, C. Desrosiers, X. Zhao, and P. Lacasse. 1999. Nitric oxide production during endotoxin-induced mastitis in the cow. J. Dairy Sci. 82:2574-2581.

Burns, F. R., C. A. Paterson, R. D. Gray, and J. T. Wells. 1990 Inhibition of Pseudomonas aeruginosa elastase and Pseudomonas keratitis using a thiol-based peptide. Antimicrob. Agents Chemother. 34:2065-2069.

Burvenich, C., V. Van Merris, J. Mehrzad, A. Diez-Fraile, and L. Duchateau. 2003. Severity of E. coli mastitis is mainly determined by cow factors. Vet. Res. 34:521-562.

Chandrakasan, G., D. A. Torchia, and K. A. Piez. 1976. Preparation of intact monomeric collagen from rat tail tendon and skin and the structure of the nonhelical ends in solution. J. Biol. Chem. 251:6062-6067.

Considine, A., A. Healy, A. L. Kelly, and P. L. H. McSweeney. 2000. Proteolytic specificity of elastase on bovine $\alpha \mathrm{s} 1$ casein. Food Chem. 69:19-26.

D’Ortho, M. P., P. H. Jarreau, C. Delacourt, I. Macquin-Mavier, M. Levame, S. Pezet, A. Harf, and C. Lafuma. 1994. Matrix metalloproteinase and elastase activities in LPS-induced acute lung injury in guinea pigs. Am. J. Physiol. 266:L209-L216.
Fang, W., and M. Sandholm. 1995. Inhibition of the proteinase activity in mastitic milk. J. Dairy Res. 62:61-68.

Fox, P. F. 1992. Indigenous enzymes in milk-proteinases. Pages 310 321 in. Advances in Dairy Chemistry, Vol. 1, Proteins, P. F. Fox, ed. Elsevier Science Publishers Ltd., London, UK.

Galis, Z. S., G. K. Sukhova, and P. Libby. 1995. Microscopic localization of active proteases by in situ zymography: Detection of matrix metalloproteinase activity in vascular tissue. FASEB J. 9:974980

Grufferty, M. B., and P. F. Fox. 1988. Milk alkaline proteinase. J. Dairy Res. 55:609-630.

Hagiwara, K., H. Yamanaka, K. Hisaeda, S. Taharaguchi, R. Kirisawa, and H. Iwai. 2001. Concentration of IL-6 in serum and whey from healthy and mastitic cows. Vet. Res. Commun. 25:99-108.

Heegaard, C. W., L. K. Rasmussen, and P. A. Andreasen. 1994. The plasminogen activation system in bovine milk: Differential localization of tissue-type plasminogen activator and urokinase in milk fractions is caused by binding to casein and urokinase receptor. Biochim. Biophys. Acta 1222:45-55.

Hotta, K., M. Niwa, A. Hara, T. Ohno, X. Wang, H. Matsuno, O. Kozawa, H. Ito, K. Kato, T. Otsuka, N. Matsui, and T. Uematsu. 2001. The loss of susceptibility to apoptosis in exudated tissue neutrophils is associated with their nuclear factor-kappa B activation. Eur. J. Pharmacol. 433:17-27.

Kaartinen, L., K. Veijalainen, P. L. Kuosa, S. Pyörälä, and M. Sandholm. 1988. Endotoxin-induced mastitis inhibition of casein synthesis and activation of the caseinolytic system. J. Vet. Med. B Infect. Dis. Vet. Public Health 35:353-360.

Koivunen, A. L., P. Maisi, Y. T. Konttinen, and M. Sandholm. 1997. Gelatinolytic activity in tracheal aspirates of horses with chronic obstructive pulmonary disease. Acta Vet. Scand. 38:17-27.

Koupparis, M. A., E. P. Diamandis, and H. V. Malmstadt. 1985. Automated stopped-flow analyser in clinical chemistry: Determination of albumin with bromocresol green and purple. Clin. Chim. Acta 149:225-235.

Larsen, L. B., and T. E. Petersen. 1995. Identification of five molecular forms of cathepsin D in bovine milk. Adv. Exp. Med. Biol. 362:279-283.

Long, E., A. V. Capuco, D. L. Wood, T. Sonstegard, G. Tomita, M. J. Paape, and X. Zhao. 2001. Escherichia coli induces apoptosis and proliferation of mammary cells. Cell Death Differ. 8:808-816.

Lopez-De Leon, A., and M. Rojkind. 1985. A simple micromethod for collagen and total protein determination in formalin-fixed paraffin-embedded sections. J. Histochem. Cytochem. 33:737743

Lowry, O. H., N. J. Rosebrough, A. L. Farr, and R. J. Randall. 1951. Protein measurement with the folin phenol reagent. J. Biol. Chem. 193:265-275.

Makowski, G. S., and M. L. Ramsby. 1996. Calibrating gelatin zymograms with human gelatinase standards. Anal. Biochem. 236:353-356.

Mehrzad, J. 2002. Respiratory burst activity and viability of bovine blood and milk neutrophils during different stages of lactation and mastitis. Ph.D. thesis. ISBN:90-5864-027-2, Ghent University, Belgium.

Mehrzad, J., H. Dosogne, E. Meyer, and C. Burvenich. 2001. Local and systemic effects of endotoxin mastitis on the chemiluminescence of milk and blood neutrophils in dairy cows. Vet. Res. 32:131-144.

Nakatsuka, M., K. Asagiri, S. Noguchi, T. Habara, and T. Kudo. 2000. Nafamostat mesilate, a serine protease inhibitor, suppresses lipopolysaccharide-induced nitric oxide synthesis and apoptosis in cultured human trophoblasts. Life Sci. 67:1243-1250.

Nickerson, S. C., and C. W. Heald. 1981. Histopathologic response of the bovine mammary gland to experimentally induced Staphylococcus aureus infection. Am. J. Vet. Res. 42:1351-1354.

Ollivier, F. J., D. E. Brooks, M. E. Kallberg, A. M. Komaromy, M. E. Lassaline, S. E. Andrew, K. N. Gelatt, G. R. Stevens, T. D. Blalock, G. B. van Setten, and G. S. Schultz. 2003. Evaluation of various compounds to inhibit activity of matrix metalloproteinases in the tear film of horses with ulcerative keratitis. Am. J. Vet. Res. 64:1081-1087. 
Özer, Z., N. Sucu, D. Düșmez, L. Tamer, A. A. Altunkan, M. Diłkmengil, and U. Oral. 2001. The effect of aprotinin on ischemia-reperfusion injury in the rabbit kidney. Pharmacol. Res. 44:455-460.

Politis, I., B. Zavizion, D. M. Barbano, and R. C. Gorewit. 1993. Enzymatic assay for the combined determination of plasmin plus plasminogen in milk: Revisited. J. Dairy Sci. 76:1260-1267.

Raser, K. J., A. Posner, and K. K. Wang. 1995. Casein zymography: A method to study mu-calpain, m-calpain, and their inhibitory agents. Arch. Biochem. Biophys. 319:211-216.

Raulo, S. M., T. Sorsa, T. Tervahartiala, T. Latvanen, E. Pirila, J. Hirvonen, and P. Maisi. 2002. Increase in milk metalloproteinase activity and vascular permeability in bovine endotoxin-induced and naturally occurring Escherichia coli mastitis. Vet. Immunol. Immunopathol. 85:137-145.

Reeves, E. P., H. Lu, H. L. Jacobs, C. G. M. Messina, S. Bolsover, G. Gabella, E. O. Potma, A. Warley, J. Roes, and A. W. Segal. 2002. Killing activity of neutrophils is mediated through activation of proteases by K+ flux. Nature 416:291-297.

Schaar, J., and H. Funke. 1986. Effect of subclinical mastitis on milk plasminogen and plasmin compared with that on sodium, antitrypsin and N-acetyl-beta-D-glucosaminidase. J. Dairy Res. 53:515-528.

Shuster, D. E., M. E. J. Kehrli, P. Rainard, and M. J. Paape. 1997. Complement fragment C5a and inflammatory cytokines in neutrophil recruitment during intramammary infection with Escherichia coli. Infect. Immun. 65:3286-3292.

Suzuki, J., M. Isobe, M. Kawauchi, M. Endoh, J. Amano, and S. Takamoto. 2000. Altered expression of matrix metalloproteinases and tissue inhibitors of metalloproteinases in acutely rejected myocardium and coronary arteriosclerosis in cardiac allografts of nonhuman primates. Transplant Int. 13:106-113.

van Meurs, J., P. van Lent, A. Holthuysen, D. Lambrou, E. Bayne, I. Singer, and W. van den Berg. 1999. Active matrix metalloproteinases are present in cartilage during immune complex-mediated arthritis: A pivotal role for stromelysin-1 in cartilage destruction. J. Immunol. 163:5633-5639.

Verdi, R. J., and D. M. Barbano. 1991. Properties of proteases from milk somatic cells and blood leukocytes. J. Dairy Sci. 74:20772081.

Verstraete, M. 1985. Clinical application of inhibitors of fibrinolysis. Drugs 29:236-261.

Weiss, S. J. 1989. Tissue destruction by neutrophils. N. Engl. J. Med. 321:327-329.

White, J. H., B. Zavizion, K. O'Hare, J. Gilmore, M. R. Guo, P. Kindstedt, and I. Politis. 1995. Distribution of plasminogen activator in different fractions of bovine milk. J. Dairy Res. 62:115-122.

Zachos, T., I. Politis, R. C. Gorewit, and D. M. Barbano. 1992. Effect of mastitis on plasminogen activator activity of milk somatic cells. J. Dairy Res. 59:461-467.

Zaoui, P., J. F. Cantin, M. Alimardani-Bessette, F. Monier, S. Halimi, F. Morel, and D. Cordonnier. 2000. Role of metalloproteases and inhibitors in the occurrence and progression of diabetic renal lesions. Diabetes Metab. 26(Suppl. 4):25-29.

Zavizion, B., J. H. White, and A. J. Bramley. 1997. Staphylococcus aureus stimulates urokinase-type plasminogen activator expression by bovine mammary cells. J. Infect. Dis. 176:1637-1640. 